\title{
Study on the Construction of the Discourse Power of Dominant Ideology in China
}

\author{
Gong Minyan
}

Xianyang Normal University, Academy of Marxism, China

Keywords: dominant ideology; discourse power, Marxism

\begin{abstract}
Dominant ideology is the soul of a country, and the spiritual belief and value pursuit of a nation. It is great significance to the construction of national ideological security. In this regard, it is advisable to construct the discourse system of dominant ideology from the three dimensions of adhering to the power of discourse of Marxist ideology, realizing the conversion of ideological political discourse to daily discourse and highlighting the Chinese elements of the power of discourse of the ideology.
\end{abstract}

In recent years, the power of discourse of dominant ideology has been a hot topic in the academic world in China, especially with the rise of new media, this aspect has gradually increased.

\section{Research Status in China}

In China, the Power of Discourse of Dominant Ideology mainly refers to Marxist ideology. Its research mainly focuses on the following aspects: The nature of the ideological concept. Ideology as 'false consciousness' is a kind of 'shadow' power (He zhonghua,1999). Marxism is premised on "correct consciousness," and therefore Marxism is the only scientific ideology (Yang shenping,2014); In China, Marxist ideology serves as a guiding ideology. It has a unitary nature. This is different from the diversity of academic styles in the academic school (Chen xianda,2010). A Study of Discourse Power of Marxist Ideology. The power of discourse of Marxist ideological is of great significance for adhering to correct orientation, enhancing value recognition, strengthening cultural self-confidence, and strengthening national political security (XIA zijun,2017); The Problem of "Threeizations" of Marxism is the power of discourse of Marxism in Nature (Han qingxiang, Chen yuanzhang, 2015). The discourse hegemony of Western countries and the strategies of "westernization" and "differentiation", information networking, and economic marketization all pose challenges to the power of discourse of Marxist ideological (Zhang ji,2010; Wang hong, Zhou qiyou,2015); In China, the status of Marxist ideological discourse is constantly changing along with changes in the economic, political systems, and ideological culture. (Tang yong,2009; Liu xianchun,2010). Research on the Turn of power of Marxist Ideology Discourse. The proper transformation of the discourse system of Marxism is an important way to strengthen Marxist ideological construction. Discourse hegemony is often hidden behind the popular discourse. The ideological discourse transformation is a self-renewal under the premise of insistence (Hou huiqin,2015). Marxist ideology has undergone a transition from a revolutionary discourse system to a constructive discourse system. It has also experienced a shift from a discourse system dominated by instrumental rationality to a discourse system dominated by value rationality (Tang aijun,2014). From the perspectives of expression, acceptance and communication, Marxist ideology has also undergone a transition from political discourse to cultural discourse (Hu boxiang,2013). The relationship between ideology and culture. With the appearance of ideology in the face of culture, it means that the ideological model cannot exclude the existence of culture, but it must gain new meaning through culture. Therefore, research on the relationship between ideology and cultural identity, cultural discourse, cultural self-confidence, cultural identity, and cultural security has gradually increased. 


\section{Value of the Discourse Power of Dominant ideology}

The power of ideological discourse mainly refers to the ability in guiding the public mind and deciding the trend of the public opinion. The "power of discourse of dominant ideology" in the party's governing discourse system mainly refers to the power of discourse and dominance of the ideology of the Marxism and the socialist core values in china. To uphold and guard the discourse of the Marxist ideology is the historic mission. At the national conference on ideological work, General Secretary Xi Jinping pointed out: "Ideological work is to consolidate the guiding role of Marxism in the ideological field and the common ideological foundation for the entire party and the people across the country.” (Xi jinping,2013)

It is to resolve social conflicts. Chinese society is experiencing profound economic transition and the "new normal" of multiple periods superimposed, where the differentiation of interests and classes has become the indisputable social reality. This manifests on the conceptual level as the differentiation and diversity of the power of ideological discourse. Especially in the context of new media, the ideological struggle is fierce. Xi Jinping pointed out that a value, if seeking to really play a role, must be integrated into social life, have itself perceived and understood by people in practice." Therefore, the dominant ideology will win the initiative and advantages in the fierce competition for the power of ideological discourse and finally enhance social cohesion and solidarity, if the Party accelerates the theoretical innovation of Marxism in a practical manner, having it better integrated with China's national conditions and fit with the development of the times (Lu weizhou,2017) and better respond to and solve social issues.

It is to integrate social ideas. The modern "market myth" has led to a daily life dominated by the logic of consumerism, while the consumption pattern of entertainment, blindness and vulgarization are strengthened. As dominated by the profit-making logic, the philosophy of exquisite selfishness and pragmatism occupies people's inner world, material possession and perceptual satisfaction replace the ideal belief and become the measure of the value of life. The irrational pursuit of secular utility drives the modern people to fall into an irrational impulse in their living, (Zhou peili,2015) and further the whole community is inundated with the chasing for money and the carnival of spending. As a result, the complete world that belongs to man is fragmented, and the daily life is filled by materials while the lofty spiritual world is collapsed, leading to the dissolution of the Marxist faith. The report of the 19th CPC National Congress pointed out that: to strengthen the party's leadership over ideological work, it desires to firmly grasp the leadership of ideological work and build a socialist ideology with strong cohesion and leading force so that all the people will be held together by the ideals, beliefs and moral values. Therefore, integrating the social ideas with the discourse of dominant Marxism ideology is a preferred approach to highlight the theme of the society and strengthen the positive energy and achieve more self-confident Chinese cultures.

\section{Building the Power of Discourse of Dominant Ideology}

Ideology is the precursor of an era and plays a fundamental role in guiding social thoughts. Spreading the current dominant ideology by using the advantages of new media and grasping the power of discourse of the dominant ideology is of great significance.

In contemporary China, to grasp the power of ideological discourse is to have the Marxism taking the leading position. "To grasp the ideological leadership is the number one priority among all leadership." (Mao Zedong,1993) Both the history and the reality have shown that occupying the position of the ideologies and solidifying the spiritual foundation for common endeavor is indispensable for the continuous development of a country and for a political party to rule a nation.

In the report of the 19th CPC National Congress, Xi Jinping proposed to strengthen the Party's leadership over ideological work and push more forwards the guiding position of Marxism in the field of ideologies. Therefore, maintaining the power of Marxist ideological discourse means to consistently upholding the Marxist position and viewpoint and supporting the leading position of Marxist ideology and the unity of guiding ideology. "It is not a true Marxist if you do not carry 
forward and develop the Marxism with new ideas and opinions." To this end, we should effectively integrate the Marxist ideological communication platform, give play to the ideological communication function of the socio-cultural community, construct a new socialist cultural ideological discourse transmission method and communication system, and make full use of classroom teaching to disseminate Marxist ideology for interpreting the spirit of Marxism.

All along, ideological discourse has always been a one-way language control, a top-down communication and political preaching, which turns the general public away from the ideology. No doubt that the characteristics of the ideology determine its rational expression. However, separated from daily life, from the practice of the masses, even the best, no matter how great the ideological theory and value system, they all will be castle in the air. In the opinion of the author, the instilling of ideology and the development of good thinking habits call for literate people more than ever. In recent years, many new media resort to words plus pictures, audio, numbers to launch down-to-earth brief summary, analysis, explanation and expression of some governmental policies and documents. This translates the discourse of "esoteric theory" and "rational discourse" into "popular theory" and "daily discourse." It is those ways of expressing conforming the masses' habits that help integrate theories into the daily life, transforming them into an easily accepted mode of thinking fitting the cognitive schemata of the public. Consequently, the leaders and the people's government come down from on high into the public, their image no longer appears to be dignified, "out of reach," rather, they show an affinity that narrows the psychological distance from the people and makes the dominant Marxist ideology agreed and accepted by the public in an imperceptible manner.

Chinese civilization is a great cultural power lasting over 5,000 years with a unique value concept and rich cultural connotation and an immortal contribution to the development of the world and human culture. As the dominant ideology of China, the Marxism, if desiring to consolidate its position on the basis of ideological and cultural pluralism and enhances its right to speak in the international arena against the dominant Western ideas, should integrate itself with traditional Chinese culture; it should carry forward the Chinese national traditions and adhere to promoting the world's identity with the Chinese path with the theoretical achievements and discourse expression of Chinese excellent traditional culture, instead of simply borrowing the words and languages of traditional culture or even grafting traditional culture into the Marxist framework. It is advisable to facilitate the intrinsic fusion of Marxism and Chinese traditional culture in practice so that Marxism has the Chinese style and national characteristics from the content to the form.(Xiao huanyuan, Qin long,2013)The report of the 19th CPC National Congress proposed an in-depth exploration of the ideological concepts, humanistic spirits and ethics embodied in the excellent Chinese traditional culture and a further innovation based on such culture in the light of the requirements of the times, keeping the Chinese culture associating with the charm and style of the times. In addition, absorbing and integrating the world-leading cultural and linguistic elements by the new media during the dissemination of China's dominant ideology is also considered necessary while properly interpreting the Chinese characteristics. "We should do a good job in propagandizing around the world and innovate ways of propaganda; efforts should be put forth on new concepts, new fields and new expression prevailing both at home and abroad, with a purpose of well delivering Chinese stories and Chinese voices.”(Xi jinping,2013)Only in this way will the power of international discourse and the internal influence and charisma be raised and the cultural confidence and cultural awareness during the ideological exchange, blending and confrontation be strengthened.

\section{Acknowledgement}

I participated in a program financial support by the National Social Science Fund of China for the research (Item Number:13XKS005). The program is Historical Evolution and Contemporary Practice of Marxist Humanistic Thought. The author obtained financial support by Shanxi province at same time. 


\section{References}

[1] Chen xianda, 2011.On Adhering to the Guiding Position of Marxist Ideology, Marxism and reality,11(6):23-29

[2] [Fr] Foucaul Editor Xu Baoqiang, 2001.Yuan Wei. The Order of Discourse [A]. The Politics of Languages and Translation [C]. Beijing: Central Compilation \& Translation Press

[3] Han qingxiang, Chen yuanzhang, 2015.The "Threeizations" and Discourse Rights of Marxism, Journal of Shanghai Normal University, (3):5-13)

[4] He zhonghua, 1999.Utopia and Pragmatism, Young thinker,4(2):36-39.

[5] Hou huiqin, 2010.Criticism of Marxist Ideology and Contemporary China. Beijing: China Social Sciences Press, 2010

[6] Hu boxiang, 2014.Interaction between Social Modernization and Ideology Security Construction in China, Academic Forum,3(3):25-28.

[7] Huang lizhi, 2008.Marxist Ideology Theory in the Perspective of Cultural Studies, Journal of Tian Jin Institute of Public Administration 3(2):19-28.

[8] Liu jianjun, 2013.Three Strategies of Ideological Work, Study of Marxism, 24(12):167-168.

[9] Li Shenming,2012. Wu Yin. 2012.Report on China’s National Conditions (First Series) . Social Sciences Academic Press,323

[10] Liu xianchun, 2010.The Contemporary Construction of Superior Discourse Power of Marxist Ideology, Journal of Shanghai Institute of Public Administration,5(5):22-29

[11] Lu Weizhou.2017. How Important the Power of Discourse of Ideologies? Journal of Guizhou Provincial Party School. 1(1):18-20

[12] Tang yong, 2009.The Change of Marxist Ideology Status in China's Discourse Right Since the Early 20th Century,China Today Forum, 6(6):27-29;

[13] Tang aijun,2014. The Discourse Transformation of Chinese Communist Party's Ideology, Journal of the Central Party School of the CPC,10(5):54-58.

[14] Wang hong, Zhu qiyou , The Impact and Construction of Discourse Power of Contemporary Marxist Ideology, 2015.Journal of Changchun University of Science and Technology12(6):1-4

[15] Works of Mao Zedong. 1999.Volume 2, p435.

[16] Xia zujun, 2017.The Epochal Review of Marxist Ideology Right of Discourse, chanbai journal,1(1):33-37

[17] Xiao Huayuan, Qin Long. 2015.Triple Dimensions for Building Public Power of Discourse of Dominant Ideology. Journal of Socialist Theory Guide. 8(8): 52-54

[18] Xi Jinping. 2013.proposed in the National Conference on Propaganda Work: Promoting Propaganda and Ideological Work with Open Mind and Broad Vision and Following the General Trend. People's Daily. Aug. 21

[19] Xi Jinping.2013. Promoting Propaganda and Ideological Work with Open Mind and Broad Vision and Following the General Trend [N]. People’s Daily. Aug. 21

[20] Yang shengping, 2014.On Williams' Understanding of the Concept of Marxist Ideology, Jianghai Journal,7(7):45-51

[21] Zhang Li.2015. Multiple Challenges and Strategic Opportunities faced by the Power of Discourse of Dominant Ideology in the Era of New Media. Journal of Xi'an University of Arts \& Science, 8(4):68-74

[22] Zhang ji, 2010.On the Basic regular pattern of Marxist Ideology Leading Social Trend of 
Thought, Journal of Hebei Normal University 5(9):5-9.

[23] Zhao haifeng, 2012.Ideological Leadership and Cultural Identity: Reflections on Marxism in China. Marxism and reality,9(5):183-189.

[24] Zhu Peili.2015. Challenges Faced by the Power of Discourse of Dominant Ideology and their Construction. Studies on the Socialism with Chinese Characteristics. (6) 